\title{
Assessment of Health Workers' Knowledge, Beliefs, Attitudes, and Use of Personal Protective Equipment for Prevention of COVID-19 Infection in Low-Resource Settings
}

\author{
M. A. Alao $\mathbb{D}^{1,2}$ A. O. Durodola, ${ }^{2,3}$ O. R. Ibrahim ${ }^{1},{ }^{4}$ and O. A. Asinobi ${ }^{5}$ \\ ${ }^{1}$ Department of Paediatrics, Bowen University Teaching Hospital, Ogbomoso, Oyo State, Nigeria \\ ${ }^{2}$ Bowen University College of Medicine Iwo, Iwo, Osun State, Nigeria \\ ${ }^{3}$ Department of Family Medicine, Bowen University Teaching Hospital, Ogbomoso, Oyo State, Nigeria \\ ${ }^{4}$ Department of Paediatrics, Federal Medical Centre, Kastina, Kastina State, Nigeria \\ ${ }^{5}$ University College Hospital Ibadan, Ibadan, Oyo State, Nigeria \\ Correspondence should be addressed to M. A. Alao; mikevikefountains@gmail.com
}

Received 14 May 2020; Revised 15 July 2020; Accepted 5 August 2020; Published 24 August 2020

Academic Editor: Carol J. Burns

Copyright (c) 2020 M. A. Alao et al. This is an open access article distributed under the Creative Commons Attribution License, which permits unrestricted use, distribution, and reproduction in any medium, provided the original work is properly cited.

\begin{abstract}
Background. Severe acute respiratory syndrome coronavirus 2 (SARS-CoV-2) is a highly infectious disease with a potential for healthcare workers (HCWs) getting infected due to inadequate protection while attending to patients. Effective use of personal protective equipment (PPE) is key to mitigating the spread of SARS-CoV-2 infection in healthcare settings. Hence, there is a need to understand HCWs' use of PPE in resource-limited settings and how closely the currently recommended guidelines for PPE are followed. This study assessed the HCWs' knowledge about, attitudes towards, beliefs on, and use of PPE to prevent SARS-CoV-2 infection in a resource-limited setting. Methods. This cross-sectional study was conducted in April 2020 in Southwest and Northwest Nigeria. The selection of participants was performed via the snowball sampling technique using a 33-item, web-based, self-administered questionnaire via a social media network. We obtained relevant sociodemographic data and information on participants' occupations and knowledge about, attitudes towards, beliefs on, and use of PPE. We analysed the data using SPSS version 23.0 for Windows (IBM, Armonk, New York, USA). A $p$ values $<0.05$ were considered statistically significant. Results. A total of 290 subjects responded to the questionnaire, and 18 (6.2\%) were excluded because of incomplete data. The mean age of the respondents was $32.3 \pm 9.9$ years. There were 116 males $(42.6 \%)$. The majority of the respondents were medical doctors (114, 41.9\%), followed by nurses and clinical students. Of the 272 respondents in this survey, only 70 (25.7\%) had adequate knowledge about PPE. Of the respondents who presumed they had adequate knowledge about donning and doffing PPE, 94 (56\%) were incorrect. The predictors of good knowledge were ages younger than 45 years $(p=0.046)$ and practice location $(p=0.009)$. Conclusion. This study showed that HCWs' knowledge about, attitudes towards, and beliefs on PPE and their PPE skill in practice in Nigeria were remarkably poor. There is an urgent need for nationwide practical training on PPE use to curtail the spread of SARS-CoV-2 infection among HCWs.
\end{abstract}

\section{Introduction}

Severe acute respiratory syndrome coronavirus 2 (SARS$\mathrm{CoV}-2)$, the pathogen that causes coronavirus disease 2019 (COVID-19), is one of the most contagious viruses in human history [1]. Following the declaration by the World Health Organization (WHO) on 11 March that COVID-19 is a pandemic disease, COVID-19 has rapidly spread across 212 countries with an estimated 4,248,389 cases and 294,046 mortalities within the five months from the start of the outbreak to 14 May 2020 [2,3]. Over a period of five weeks, the number of COVID-19 cases in Nigeria rose from 38 cases on 24 March to 4,791 cases by 14 May 2020 [2]. This ravaging infection has spread beyond boundaries and race and has a predilection for senior citizens. 
Containment of this disease has been a major problem despite the numerous protocols advanced by various regulatory bodies. These guidelines and protocols include those by the WHO, the Centers for Disease Control, the International Labour Organization, and the European Agency for Safety and Health to prevent infections among healthcare and nonhealthcare workers [3-6]. They include facility cleaning, regular and proper handwashing, respiratory hygiene and etiquette, advice on national travel, emphasis on staying at home for infection containment, events and meeting arrangement rules, case notification and management, and proper use of face masks [3-7]. Among the critical components of infection and prevention control (IPC) during the management of COVID-19 is the mandatory use of PPE by healthcare workers (HCWs) [8]. This component is a safeguard, as HCWs are at greater risk of contracting the disease $[9,10]$. In Nigeria as on the 1st of May, approximately 113 HCWs have been infected with SARS-CoV-2 during their duties $[11,12]$.

PPE is a physical barrier worn by HCWs to prevent spreading of a pathogen from either a suspected or confirmed case or a pathologic specimen. It serves the dual role of preventing disease spread from patients to HCWs and vice versa. These physical barriers include goggles, face shields, fluid-resistant medical or surgical masks, particulate respirators (e.g., powered air-purifying and N95 respirators), gloves, disposable gowns, disposable coveralls, waterproof or heavy duty aprons, waterproof boots, and hoods or headcovers in conjunction with other IPC methods $[9,13,14]$.

$\mathrm{Wu}$ et al. [15] and the National Hospital Infection Management and Quality Control Centre recently reported a large-scale infection of HCWs from the Hubei province in China that was mainly due to underutilisation of PPE $[8,15]$. Similarly, the Henry Ford Health System recently confirmed that $46.6 \%$ of its workers had been infected with SARS-CoV2 [16]. The consequence of these reports $[15,16]$ is fear among HCWs in the setting of a lack of definitive treatment or a vaccine for SARS-CoV-2. This situation necessitates critical observation of occupational hazards and workplace safety during the COVID-19 pandemic. HCWs in low-resource settings need adequate PPE skill (including appropriately selection, donning, removal, decontamination, and disposal of PPE) at the backdrop of good theoretical knowledge of the indications and procedures, for effective protection in clinical areas. They should also have the right attitudes towards, training on, approaches to, and beliefs on and the requisite skills for PPE in practice in addition to other interventions to successfully fight and win the battle against SARS-CoV-2.

The need, therefore, to evaluate HCWs' knowledge about, attitudes towards, beliefs on, and use of PPE become imperative to identifying gaps and facilitating prompt intervention during the COVID-19 pandemic.

\section{Subjects and Methods}

This cross-sectional study took place in April 2020 in two purposively selected geopolitical zones in the country (Southwest and Northwest Nigeria) as a nationwide survey may not be a true representation in view of the sampling technique.

The Institutional Research Ethics Review Committee approved the research with the reference number BUTH/ REC/-055.

As a result of nationwide mandatory lockdown and the concern for interviewers' safety, the researcher opted for an online survey using a Google form administered via the WhatsApp platform [17], the most widely used social media platform in Nigeria [18]. At the beginning of the questionnaire, each respondent was introduced to the survey. Their voluntary participation was sought, and an electronic consent was obtained. Potential participants who declined to click on the "yes" option for consent cannot proceed to access the survey.

The sample size was estimated using a $43.4 \%$ PPE utilization rate in a similar study in Cyprus due to limited local data on the level of utilization of PPE among HCWs in Nigeria. A sample of 262 was obtained at $95 \%$ confidence interval and $6 \%$ margin of error. However, 290 responded to the survey, but 18 were excluded in the final data analysis due to incomplete data.

We included health workers who are in active service in any of the Nigerian hospitals and have access to the Internet. Responses with incomplete information were excluded from the data analysis.

We obtained the list of HCWs' groups and associations of state chapters in Nigeria to form the sample frame. Thirty percent of the number on the list of associations and groups (assumed to be adequate) were selected by simple random selection to form the snowball seeds for the study [19].

A semistructured questionnaire [20] was synthesised from the WHO training manual for PPE and from the existing literature (summarized in Table 1) to obtain relevant sociodemographic data, knowledge about PPE, attitude towards PPE, beliefs, and level of PPE skill of each participant.

Prior to commencement of the study, a pilot study was carried out to validate the questionnaire. The Google form questionnaire was also peer-reviewed by faculty members of the Department of Public Health, Bowen University Teaching Hospital, the Paediatric Department, University College Hospital Ibadan, and the Infectious Disease Unit, Federal Medical Centre Kastina, Kastina State, Northwest Nigeria.

A Google form questionnaire link was sent to the various HCWs' close user WhatsApp groups and associations which included the nurses, the medical doctors, the physiotherapists, and the laboratory scientists across the selected geopolitical zones in the country. The heads of the groups and associations were contacted to encourage participation of members in the survey. Each respondent was encouraged to send the link to other HCWs' close user groups for participation (chain-referral sampling technique).

Seven questions assess the knowledge of the participants. Each question has an option of "either yes, no, or not sure as the most appropriate response." A correct response to the question scores one mark, while a wrong answer attracts zero [21]. The mean score of the seven items was determined. 
TABLE 1: Summary of the semistructured questionnaire.

\begin{tabular}{lcc}
\hline Questions & Domain assessed & Explanatory note \\
\hline Questions 1-7 & General knowledge of health workers on PPE & Good and poor based on a score $\geq$ mean knowledge score \\
Questions 8-10 & Training of health workers on PPE & Assesses how the health workers are trained on PPE \\
Questions 11-18 & The health workers PPE skill in practice & Assesses how to select, wear, remove, and discard PPE \\
Questions 19-23 & The health workers attitude to PPE & Assesses the attitude of health workers to use of PPE \\
Questions 24-28 & The health workers belief on PPE & Assesses the believes of health workers towards use of PPE \\
Questions 29-33 & The sociodemographics of the respondents & Age, gender, occupation, and practice location \\
\hline
\end{tabular}

PPE: personal protective equipment.

Scores $\geq$ the mean score were credited as good knowledge score and poor if otherwise.

The HCWs' PPE skill in practice was assessed with a set of 10 questions. The mean score was obtained. Subjects with scores $\geq$ the mean score were also deemed to have adequate skill [21, 22]. The Likert scale consisting of five grades of responses was used to assess attitudes and beliefs. Similar estimates as described above for knowledge and skill were used for attitude and belief scores. In addition to the above, the questionnaire also inquired about participants' view on locally made PPE which includes sewn face masks made of fabric material, coverall gown made of waterproof synthetic materials, and face shield produced from plastic bags as shown in the image on the questionnaire from one of the centers in Northwestern Nigeria as opposed to imported supplies from Europe, China, USA, and Germany.

Data were entered into a password-encrypted computer and subsequently analysed using IBM Statistical Package for Social Sciences (SPSS) version 23.0 for Windows (IBM, Armonk, New York, USA). $p$ values of $<0.05$ were considered significant. Categorical variables were summarized using frequencies, ratios, and proportions, while the chisquare or Fisher's exact test was used to determine the association between the variables. We assessed the variables that were statistically significant on bivariate analysis for predictors of good knowledge and good PPE skill in practice using multivariate logistic regression.

\section{Results}

A total of 290 subjects responded to the questionnaire, and 18 (6.2\%) were excluded because of incomplete data. The mean age of the study population was $32.3 \pm 9.9$ years. One hundred and sixteen were males (42.6\%), giving a $\mathrm{M}: \mathrm{F}$ ratio of $1: 1.3$. The majority of the respondents were medical doctors 114 (41.9\%), followed by nurses and clinical students as shown in Table 2. The larger proportions of the respondents were from tertiary health facilities $(206(75.6 \%))$.

Table 3 shows the responses of the participants to questions on general knowledge of PPE. Although 270 $(99.3 \%)$ of the respondents were aware of PPE, only 38 (14.0\%) know that the standard PPE list extends to 8-11 items. About half (134 (49.3\%)) of the respondents correctly admitted that there were 4 levels of PPE utilization. When the picture of a level A PPE suit was shown, only a third (74 $(27.2 \%)$ ) could identify the image correctly.

Table 4 shows training of human capacity on PPE: 130 (47.8\%) HCWs had training on PPE and half (64 (23.5\%))
TABle 2: Sociodemographic characteristics.

\begin{tabular}{lcc}
\hline Sociodemographics & Frequency & Percent \\
\hline Age & 88 & \\
$<25$ & 102 & 32.4 \\
$26-35$ & 58 & 37.5 \\
$36-45$ & 12 & 21.3 \\
$46-55$ & 10 & 4.4 \\
$56-65$ & 2 & 3.7 \\
$>65$ & & 0.7 \\
\hline Gender & 156 & \\
Female & 116 & 57.4 \\
Male & & 42.6 \\
\hline Level of health & 206 & \\
Tertiary & 40 & 75.7 \\
Secondary & 26 & 14.7 \\
Primary & & 9.6 \\
\hline Occupation & 114 & \\
Medical doctors & 72 & 41.9 \\
Clinical students & 72 & 26.5 \\
Nurses & 8 & 26.5 \\
Laboratory scientist & 4 & 2.9 \\
Optician & 2 & 1.5 \\
Physiotherapist & & 0.7 \\
\hline Place of practice & 610 & 77.2 \\
Southwest & 68 & 10.3 \\
Northwest & 6.9 \\
Northcentral & 6.2 \\
Northeast & 6.2 \\
Southeast & & \\
South-south & & \\
\hline
\end{tabular}

had the training for more than six months prior to the outbreak of SARS-CoV-2 infection. The main source of training was via in-person seminars (68 (25.0\%)), followed by the social media networks such as Facebook, Twitter, and WhatsApp.

Of note is the fact that younger subjects ( $\leq 45$ years), both the nurses $(44(16.2 \%))$ and medical students (44 $(16.2 \%))$, were more knowledgeable about PPE among the various cadre of HCWs compared with the residents (26 $(9.6 \%))$ and medical consultants $(28(10.3 \%))(p=0.01)$ as shown in Table 5. Regarding having the essential knowledge for selection and safe use of gloves, only 38/272 (14.0\%) know the recommended glove for PPE and the need to read the biohazard safety instruction on the glove's packs for optimal use.

With respect to HCWs' PPE skill in practice (Table 6), 174 (64.0\%) admitted to have used PPE before but less than 
TABLe 3: General knowledge of respondents on PPE.

\begin{tabular}{|c|c|c|c|}
\hline Questions & Responses & Frequency & Percent \\
\hline \multirow{2}{*}{ Have you heard of PPE before? } & No & 2 & 0.7 \\
\hline & Yes & 270 & 99.3 \\
\hline \multirow{3}{*}{ Do you know what personal protective equipment is? } & No & 12 & 4.4 \\
\hline & Yes & 220 & 80.9 \\
\hline & Not sure & 40 & 14.7 \\
\hline \multirow{4}{*}{ How many types (items) of PPE do you know? } & $1-2$ & 42 & 15.4 \\
\hline & $3-4$ & 74 & 27.2 \\
\hline & $5-8$ & 118 & 43.4 \\
\hline & $8-11$ & 38 & 14.0 \\
\hline \multirow{5}{*}{ How many levels of protection are associated with PPE utilization? } & Two & 44 & 16.2 \\
\hline & Three & 76 & 27.9 \\
\hline & Four & 134 & 49.3 \\
\hline & Five & 6 & 2.2 \\
\hline & I do not know & 12 & 4.4 \\
\hline \multirow{4}{*}{ What level of PPE is demonstrated below } & Level A & 74 & 27.2 \\
\hline & Level B & 34 & 12.5 \\
\hline & Level C & 80 & 29.4 \\
\hline & Level D & 84 & 30.9 \\
\hline \multirow{3}{*}{ Do you know the indications for PPE? } & No & 14 & 5.1 \\
\hline & Yes & 224 & 82.4 \\
\hline & Not sure & 34 & 12.5 \\
\hline \multirow{3}{*}{$\begin{array}{l}\text { Do you know if the gloves worn protects you against specific types of viral pathogen like SARS-CoV- } \\
2\end{array}$} & Yes & 70 & 25.7 \\
\hline & No & 76 & 27.9 \\
\hline & Not sure & 126 & 46.3 \\
\hline
\end{tabular}

PPE: personal protective equipment; SARS-CoV-2: severe acute respiratory syndrome coronavirus 2.

TABLE 4: Training of respondents on PPE.

\begin{tabular}{lcc}
\hline Training & Yes/correct response $(n)$ & Percentage \\
\hline Trained on PPE & 130 & 47.8 \\
Less than 3 months ago & 54 & 14.9 \\
Three to six months ago & 64 & 5.1 \\
More than 6 months ago & \\
\hline Sources of training & 30 \\
Training on social media platforms Facebook, Twitter, and WhatsApp & 68 \\
In-person seminar & 18 \\
Class room lectures & 23.5 \\
In-person on job training & 12 \\
Online modular training & 12 \\
\hline
\end{tabular}

half $80 / 174(46.0 \%)$ knows how to correctly select appropriate PPE for use. When asked questions about wearing and removing PPE, of the 108 (39.7\%) who assumed they had the requisite knowledge of these procedures, only 18 (6.6\%) and $34(12.5 \%)$ know the correct sequence for donning and removal of PPE, respectively. Better PPE skills were demonstrated by the younger nurses $32(11.8 \%)$ compared to other members of the health team $(p=0.001)$ as shown in Table 7. Two hundred and fourteen (78.7\%) admitted that they will definitely use PPE if available. Using the Likert scale, twelve $(4.4 \%)$ of the study participants always use PPE in the course of attending to patients.

Table 8 and Figure 1 show the attitude of the HCWs towards and their beliefs on PPE. Generally, the attitude of HCWs towards PPE was poor (14.5\%) as shown in Figure 1.

Sixty-six $(24.2 \%)$ of the respondents believe that the available PPE is of good quality at most. Eighty six (31.6\%) believe that the quality of locally made PPE such as face masks, face shield, and coverall gowns compares favourably well with the imported brands from USA, Europe, China, and Germany as shown in Table 8. Other details are shown in Table 8.

The only predictors of good knowledge of PPE was age. The unadjusted odds were $\beta=1.32, \mathrm{OR}=3.8$ (95\% CI: $1.4-10.0), p=0.009$. When adjusted for age younger than 45 years, the odds were $\beta=1.137, \mathrm{OR}=3.1$ (95\% CI: $1.0-9.7$ ).

The predictors for good PPE practice skill were age and place of practice. The unadjusted and adjusted odds for age younger than 45 years for good PPE practice skill were $\beta=1.689, \quad \mathrm{OR}=5.4 \quad$ (95\% CI: $2.1-13.9), \quad p=0.0001$ and $\beta=0.903$, OR $=2.5$ (95\% CI: $1.0-6.0), \quad p=0.046$, respectively. In terms of HCWs' practice location, the unadjusted odds for Southwest and Northwest Nigeria and the adjusted odds for Southwest Nigeria were $\beta=1.516, \mathrm{OR}=4.6(95 \%$ CI: $1.5-14.2), p=0.009$ and $\beta=1.227, \mathrm{OR}=3.4$ (95\% CI: $1.3-9.3)$, respectively. 
TABLE 5: Association between sociodemographic characteristics and knowledge of respondents about PPE.

\begin{tabular}{|c|c|c|c|c|}
\hline Sociodemographic & Poor knowledge $n(\%)$ & Good knowledge $n(\%)$ & $\chi^{2}$ & $p$ value \\
\hline Age & & & 15.773 & 0.006 \\
\hline$<25$ & $36(13.2)$ & $52(19.1)$ & & \\
\hline $26-35$ & $56(20.6)$ & $46(16.9)$ & & \\
\hline $36-45$ & $16(5.9)$ & $42(15.4)$ & & \\
\hline $46-55$ & $4(1.5)$ & $8(2.9)$ & & \\
\hline $56-65$ & $2(0.7)$ & $8(2.9)$ & & \\
\hline$>65$ & $0(0.0)$ & $2(0.7)$ & & \\
\hline Gender & & & 6.960 & 0.008 \\
\hline Male & $38(14.0)$ & $78(28.7)$ & & \\
\hline Female & $76(27.9)$ & $80(29.4)$ & & \\
\hline Level of healthcare & & & 2.308 & 0.315 \\
\hline Primary & $14(5.1)$ & $12(4.4)$ & & \\
\hline Secondary & $14(5.1)$ & $26(9.6)$ & & \\
\hline Tertiary & $86(31.6)$ & $120(44.1)$ & & \\
\hline Occupation & & & 11.311 & 0.010 \\
\hline Clinical student & $28(10.3)$ & $44(16.2)$ & & \\
\hline Nurses & $28(10.3)$ & $44(16.2)$ & & \\
\hline Lab scientist & $6(2.2)$ & $2(0.7)$ & & \\
\hline Optician & $0(0.0)$ & $4(1.5)$ & & \\
\hline Consultant & $10(3.7)$ & $28(10.3)$ & & \\
\hline Residents & $30(11.0)$ & $26(9.6)$ & & \\
\hline House physician & $12(4.4)$ & $8(2.9)$ & & \\
\hline Physiotherapist & $0(0.0)$ & $2(0.7)$ & & \\
\hline Place of practice & & & 13.004 & 0.016 \\
\hline Southwest & $94(34.6)$ & $116(42.6)$ & & \\
\hline South-south & $0(0.0)$ & $6(2.2)$ & & \\
\hline Northeast & $2(0.7)$ & $4(1.5)$ & & \\
\hline Northwest & $6(2.2)$ & $22(8.1)$ & & \\
\hline Northcentral & $10(3.7)$ & $6(2.2)$ & & \\
\hline Southeast & $2(0.7)$ & $4(1.5)$ & & \\
\hline
\end{tabular}

$\chi^{2}$ : chi-square test; $p$ value $<0.05$ (i.e., statistically significant).

TABLE 6: Healthcare workers' PPE skill in practice $(N=272)$.

\begin{tabular}{|c|c|c|}
\hline Question & Frequency & Percentage \\
\hline Have you ever used PPE before? & 174 & 64.0 \\
\hline Have you ever seen PPE used before? & 244 & 89.7 \\
\hline Does your facility have any policy on PPE use? & 134 & 49.3 \\
\hline Do you know how to correctly select PPE? & 80 & 29.4 \\
\hline Respondents who know how to correctly wear and remove PPE? & 108 & 39.7 \\
\hline Respondents with correct knowledge of donning PPE & 18 & 6.6 \\
\hline Respondents with correct knowledge of doffing of PPE & 34 & 12.5 \\
\hline Respondents with correct knowledge of decontamination and or disposal PPE & 110 & 40.4 \\
\hline $\begin{array}{l}\text { Do you utilize the recommendations on the glove packet including biohazard symbol to make informed choice of } \\
\text { the appropriate glove to wear? }\end{array}$ & 90 & 33.1 \\
\hline \multicolumn{3}{|l|}{ How often do you wear PPE? } \\
\hline Never & 52 & 19.1 \\
\hline Rarely & 56 & 20.6 \\
\hline Occasionally & 92 & 33.8 \\
\hline Often & 60 & 22.1 \\
\hline Always & 12 & 4.4 \\
\hline
\end{tabular}

\section{Discussion}

In the prevention of workplace hazards, HCWs' knowledge, attitudes, and beliefs are paramount if any success in containment is to be achieved. Our study showed that HCWs had poor knowledge about PPE. Only $14.0 \%$ of the respondents knew what constituted standard PPE. The observed low knowledge about PPE among HCWs in this study is similar to that in a report by Wang et al. [8] in the Hubei province of China and the previously reported knowledge of HCWs among individuals who cared for patients with Ebola infection in Southeast Nigeria [23]. The finding of nurses and medical students being more knowledgeable about PPE than the older senior colleagues 
TABLe 7: Association between sociodemographic characteristics and healthcare workers' PPE skills.

\begin{tabular}{|c|c|c|c|c|}
\hline Sociodemographics & Poor skills $n(\%)$ & Good skills $n(\%)$ & $x^{2}$ & $p$ value \\
\hline Age & & & 14.428 & 0.011 \\
\hline$<25$ & $48(17.6)$ & $40(14.7)$ & & \\
\hline $26-35$ & $72(26.5)$ & $30(11.0)$ & & \\
\hline $36-45$ & $34(12.5)$ & $24(8.8)$ & & \\
\hline $46-55$ & $6(2.2)$ & $6(2.2)$ & & \\
\hline $56-65$ & $2(0.7)$ & $8(2.9)$ & & \\
\hline$>65$ & $2(0.7)$ & $0(0.0)$ & & \\
\hline Gender & & & 0.975 & 0.323 \\
\hline Male & $66(24.3)$ & $50(18.4)$ & & \\
\hline Female & $98(36.0)$ & $58(21.3)$ & & \\
\hline Level of healthcare & & & 1.596 & 0.450 \\
\hline Primary & $18(6.6)$ & $8(2.9)$ & & \\
\hline Secondary & $26(9.6)$ & $14(5.1)$ & & \\
\hline Tertiary & $120(44.1)$ & $86(31.6)$ & & \\
\hline Occupation & & & 12.278 & 0.001 \\
\hline Clinical students & $46(16.9)$ & $26(9.6)$ & & \\
\hline Nurses & $40(14.7)$ & $32(11.8)$ & & \\
\hline Laboratory scientist & $8(2.9)$ & $0(0.0)$ & & \\
\hline Optician & $4(1.5)$ & $0(0.0)$ & & \\
\hline Consultant & $14(5.1)$ & $24(8.8)$ & & \\
\hline Residents & $40(14.7)$ & $16(5.9)$ & & \\
\hline House physician & $12(4.4)$ & $8(2.9)$ & & \\
\hline Physiotherapist & $0(0.0)$ & $2(0.7)$ & & \\
\hline Place of practice & & & 7.254 & 0.199 \\
\hline South West & $130(47.8)$ & $80(29.4)$ & & \\
\hline South South & $2(0.7)$ & $4(1.5)$ & & \\
\hline North East & $2(0.7)$ & $4(1.5)$ & & \\
\hline North West & $16(5.9)$ & $12(4.4)$ & & \\
\hline North Central & $12(4.4)$ & $4(1.5)$ & & \\
\hline South East & $2(0.7)$ & $4(1.5)$ & & \\
\hline
\end{tabular}

$\chi^{2}$ : chi-square test; $p$ value $<0.05$ (i.e., statistically significant).

although unexpected corroborates the inverse relationship of increasing years of experience and HCWs knowledge of PPE reported by authors $[24,25]$. The suggested reasons for HCWs' poor knowledge about PPE included a lack of HCW training and paucity of retraining of HCWs on PPE, lack of expertise to conduct this training, and a false assumption that epidemics of contagious diseases are rare and acquiring related knowledge may be a futile effort. Perhaps the findings could also represent a higher visibility of younger digital native HCWs to access readily available up-to-date information on PPE compared with the older digital native colleagues who use a more rigorous process to access information from textbooks and journal articles. Perhaps, the disproportionate involvement of older colleagues with nonclinical responsibility such as managerial duties in addition to the aforementioned reason may also be suggested for the disparity observed among the age groups.

In the containment of contagious diseases, the consequences of HCWs having poor knowledge are multifaceted. The workers are not only at risk of contracting infections but also serve as hosts to rapidly spread the disease within a short period. This study's findings of HCWs' poor knowledge about the indications for and selection of appropriate PPE are consistent with the observations by Chia et al. [26] in Singapore during the SARS-CoV outbreak in 2003 in which more than half of the nurses and clerical staff agreed that paper face masks serve a similar function to surgical masks.

Despite the fact that approximately half of the respondents had some form of training on PPE, only $6.6 \%$ and $12.5 \%$ knew the correct procedure to don and remove PPE, respectively. A study in the United States assessed the doffing practices of HCWs and found that in $90 \%$ of cases, the selection and/or the sequence of doffing PPE was incorrect [27]. Another study in the United States found that $100 \%$ and $27 \%$ of HCWs at least breached the protocol for Ebola for donning and doffing PPE, respectively [28]. The high levels of breaches of the protocol in wearing and removal of PPE could be attributed to the complexity of the protocols and the need for training and retraining. Following the appropriate steps is important to avoiding self-contamination when utilizing PPE. Perhaps, the poor skill about and practice of donning and removing PPE may partly explain the high rate of HCW infections in Nigeria during the COVID-19 outbreak [29].

Concerning is the level PPE skill observed among the medical doctors as compared to the nurses. Nurses were observed to have better performance than the other HCWs in utilizing PPE in tandem with the reports in the literature $[24,25]$. The reason for this disparity is not very clear; however, it is possible that a higher proportion of specialist 
TABLE 8: Attitudes and beliefs of health workers towards the use of PPE.

Questions on PPE
Will you be willing to put on the highest level of PPE when the need arises? Should patients' safety
be your first choice?

Are you willing to use the PPE provided by your facility in the wake of COVID-19 pandemic?

Do you feel taking your lab coat/ward home is not harmful?

Do you feel following strict rules in removing gloves, face shield, and goggles is mandatory?

Questions on beliefs of health workers on PPE

Do you believe the available PPE is of standard quality?

Do you believe that PPE is required by only some special health worker?

Is your present level of knowledge of PPE adequate?

Do you believe the available PPE is effective in preventing infectious disease?

Do you believe locally manufactured PPE is as good as imported ones

\begin{tabular}{|c|c|c|}
\hline Responses & Frequency & Percent \\
\hline Definitely not & 2 & 0.7 \\
\hline Probably not & 4 & 1.5 \\
\hline Probably & 24 & 8.8 \\
\hline Possibly & 28 & 10.3 \\
\hline Definitely & 214 & 78.7 \\
\hline Definitely not & 2 & 0.7 \\
\hline Probably not & 2 & 0.7 \\
\hline Probably & 32 & 11.8 \\
\hline Possibly & 28 & 10.3 \\
\hline Definitely & 208 & 76.5 \\
\hline $\begin{array}{l}\text { Strongly } \\
\text { disagree }\end{array}$ & 154 & 56.6 \\
\hline Disagree & 86 & 31.6 \\
\hline Undecided & 14 & 5.1 \\
\hline Agree & 6 & 2.2 \\
\hline Strongly agree & 12 & 4.4 \\
\hline $\begin{array}{l}\text { Strongly } \\
\text { disagree }\end{array}$ & 2 & 0.7 \\
\hline Undecided & 12 & 4.4 \\
\hline Agree & 92 & 33.8 \\
\hline Strongly agree & 166 & 61 \\
\hline $\begin{array}{l}\text { Strongly } \\
\text { disagree }\end{array}$ & 58 & 21.3 \\
\hline Disagree & 100 & 36.8 \\
\hline undecided & 24 & 8.8 \\
\hline Agree & 52 & 19.1 \\
\hline Strongly agree & 38 & 14 \\
\hline $\begin{array}{l}\text { Very poor } \\
\text { quality }\end{array}$ & 2 & 0.7 \\
\hline Poor quality & 30 & 11 \\
\hline Fair quality & 174 & 64 \\
\hline Good quality & 58 & 21.3 \\
\hline $\begin{array}{l}\text { Excellent } \\
\text { quality }\end{array}$ & 8 & 2.9 \\
\hline $\begin{array}{l}\text { Strongly } \\
\text { disagree }\end{array}$ & 92 & 33.8 \\
\hline Disagree & 128 & 47.1 \\
\hline Undecided & 6 & 2.2 \\
\hline Agree & 32 & 11.8 \\
\hline Strongly agree & 14 & 5.1 \\
\hline Very poor & 20 & 7.4 \\
\hline Poor & 82 & 30.1 \\
\hline Fair & 116 & 42.6 \\
\hline Good & 46 & 16.9 \\
\hline Excellent & 8 & 2.9 \\
\hline Definitely not & 20 & 7.4 \\
\hline Probably not & 54 & 19.9 \\
\hline Probably & 82 & 30.1 \\
\hline Possibly & 44 & 16.2 \\
\hline Definitely & 72 & 26.5 \\
\hline $\begin{array}{l}\text { Strongly } \\
\text { disagree }\end{array}$ & 22 & 8.1 \\
\hline Disagree & 56 & 20.6 \\
\hline Undecided & 108 & 39.7 \\
\hline Agree & 76 & 27.9 \\
\hline Strongly agree & 10 & 3.7 \\
\hline
\end{tabular}




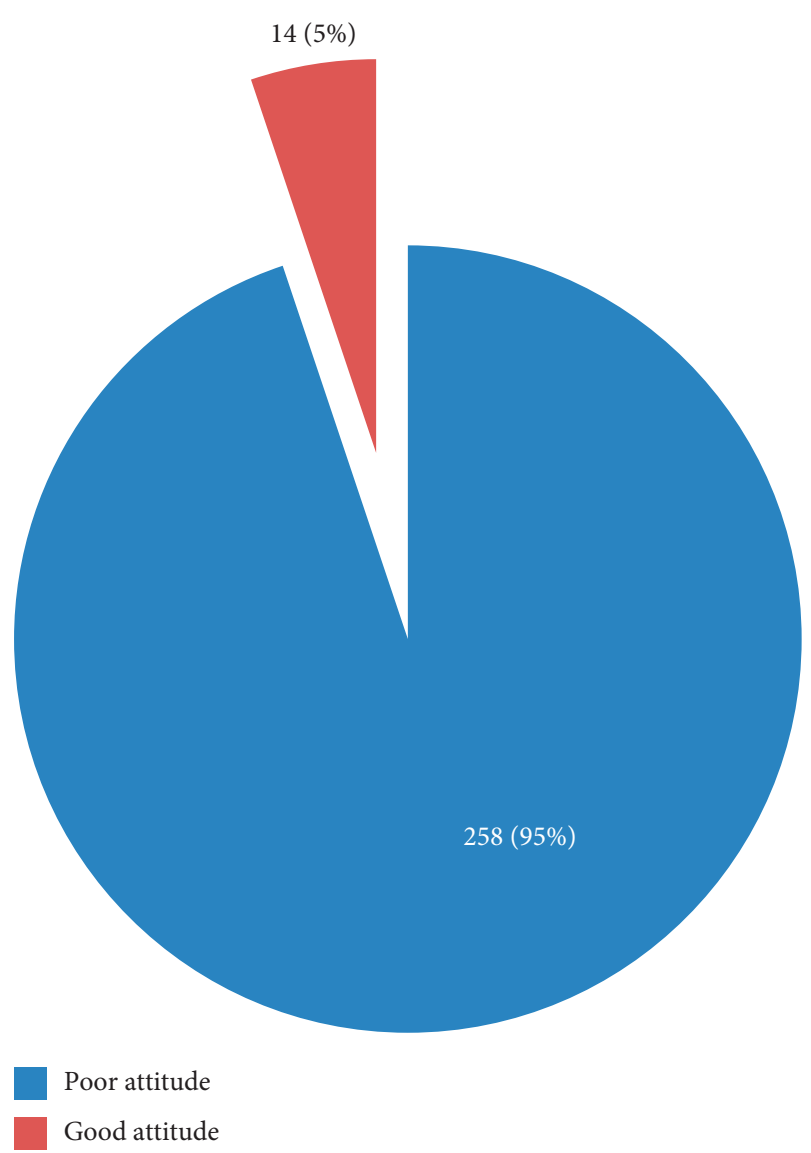

Figure 1: Attitude of respondents towards personal protective equipment.

nurses who work in the theatre and intensive care unit participated in the survey. They are regularly exposed to using PPE as a routine in the course of their clinical duty. It is also plausible to suggest that lack of immediate health consequences from previous accidental exposure to unsafe practices by older HCWs could have given a false confidence of not requiring PPE skill in practice.

Institution and execution of countermeasures for infection control and prevention (ICP) measures should include continual medical education of HCWs on ICP with emphasis on the participation of HCWs older than 45 years. Constitution of an effective safety committee, organization of scheduled and impromptu performancebased evaluation, and addressing the perceived barrier in compliance with these guidelines such as perceived difficulty with communication particularly with elderly patients and addressing the perceived discomfort associated with wearing the PPE such as maintaining cool ambient temperature in healthcare settings are paramount [24].

Our study also shows poor attitudes towards the use of PPE, as less than 5.0\% admitted using PPE when required. This rate is lower than the $55.0 \%$ compliance found among Chinese HCWs during the 2009 pandemic, the $52 \%$ compliance reported by McGaw et al. [30] among physicians, and the $65 \%$ compliance among nurses in Jamaica [31]. The poor attitudes towards using PPE are concerning, as nosocomial COVID-19 infections among HCWs will have negative consequences in low-middle-income countries like Nigeria, where there is already an inadequate supply of healthcare personnel. The poor attitudes towards PPE use may be due to nonavailability, increased pressure on merger consumables, or global shortage of PPE, as approximately three-quarters of the respondents were willing to use PPE if it was made available by the facility.

The finding that only one-third of the respondents' believe that the available PPE were adequate for infection prevention calls for an audit and a review of the quality/ specifications and suitability of PPE in the current use in the healthcare setting in the study locations.

This study also showed that 6 out of 10 HCWs believed that the quality of PPE available in the market was of fair quality. This observation could encourage the use of PPE, with HCWs having confidence in the protection offered during usage. PPE is meant to protect HCWs from infection during the course of their work [32].

4.1. Limitation. The present survey is not without its limitations. The feasible web-based online nature of the survey and the purposive sampling techniques could have excluded individuals from the study.

In the course of the survey, an intense apathy of the HCWs to participate in the survey was observed either consequent to increased work load/stress level, additional cost of mobile data utilized in accessing the survey, overt lack of interest, or multiple survey fatigue at the time of the study which could have excluded some of the HCWs from participating. All of these limits the generalisability of the result and calls for careful interpretation. It is also reasonable to suspect that the responses from the self-administered questionnaire may not always represent the true/honest position of the respondents. However, respondents were encouraged to be honest and assured their responses were anonymous.

\section{Conclusion}

This study showed that HCWs' knowledge about, attitudes towards, beliefs on, and use of PPE in Nigeria were remarkably poor. There is an urgent need for nationwide practical training on PPE to curtail the spread of SARS-CoV2 infection among HCWs.

\section{Data Availability}

All data are fully available to all interested researchers upon request without restrictions from the corresponding author or from the Director of Clinical Services, Bowen University Teaching Hospital, Ogbomosho (adewumi.durodola@ bowen.edu.ng).

\section{Ethical Approval}

Ethical approval was obtained from the Health Research Ethical Committee of the Bowen University Teaching Hospital with the approval number BUTH/REC/-055. 


\section{Consent}

Informed consent was obtained from all participants for this study.

\section{Conflicts of Interest}

The authors declared no potential conflicts of interest with respect to the research, authorship, and/or publication of this article.

\section{Authors' Contributions}

MAA substantially contributed to conception or design; contributed to acquisition, analysis, or interpretation of data; drafted the manuscript; critically revised the manuscript for important intellectual content; gave final approval; and agrees to be accountable for all aspects of the work in ensuring that questions relating to the accuracy or integrity of any part of the work are appropriately investigated and resolved. AOD contributed to conception or design; critically revised manuscript; gave final approval; and agrees to be accountable for all aspects of work ensuring integrity and accuracy. ROI substantially contributed to the design, acquisition, analysis, or interpretation of data; critically revised the manuscript; gave final approval; and agrees to be accountable for all aspects of work ensuring integrity and accuracy. AOA contributed to design and acquisition; critically revised the manuscript; gave final approval; and agrees to be accountable for all aspects of work ensuring integrity and accuracy.

\section{References}

[1] J. F.-W. Chan, K.-H. Kok, Z. Zhu et al., "Genomic characterization of the 2019 novel human-pathogenic coronavirus isolated from a patient with atypical pneumonia after visiting Wuhan," Emerging Microbes \& Infections, vol. 9, no. 1, pp. 221-236, 2020.

[2] World Health Organization, Coronavirus Disease 2019 (COVID-19): Situation Report, World Health Organization, Geneva, Switzerland, 2020.

[3] C. Sohrabi, Z. Alsafi, N. O’Neill et al., "World Health Organization declares global emergency: a review of the 2019 novel coronavirus (COVID-19)," International Journal of Surgery, vol. 76, pp. 71-76, 2020.

[4] CDC Coronavirus Disease, (COVID-19): Schools, Workplaces, \& Community Locations, US Department of Health and Human Services, CDC, Atlanta, GA, USA, 2019, https://www.cdc.gov/ coronavirus/2019-ncov/community/index.html?CDC_AA_refV $\mathrm{al}=\mathrm{https} \% 3 \mathrm{~A} \% 2 \mathrm{~F} \% 2 \mathrm{Fwww} . c d c . g o v \% 2 \mathrm{Fcoronavirus} \% 2 \mathrm{~F} 2019$-nc ov\%2Fpreparing-individualscommunities.html.

[5] M. S. Razai, K. Doerholt, S. Ladhani, and P. Oakeshott, "Coronavirus disease 2019 (covid-19): a guide for UK GPs," BMJ, vol. 368, p. m800, 2020.

[6] S. Ambigapathy, G. S. Rajahram, U. K. Shamsudin et al., "How should front-line general practitioners use personal protective equipment (PPE)?," Malaysian Family Physician, vol. 15, pp. 2-5, 2020.

[7] R. M. Anderson, H. Heesterbeek, D. Klinkenberg, and T. D. Hollingsworth, "How will country-based mitigation measures influence the course of the COVID-19 epidemic?," The Lancet, vol. 395, no. 10228, pp. 931-934, 2020.

[8] J. Wang, M. Zhou, and F. Liu, "Reasons for healthcare workers becoming infected with novel coronavirus disease 2019 (COVID-19) in China," Journal of Hospital Infection, vol. 105, no. 1, pp. 100-101, 2020.

[9] World Health Organization, Rational Use of Personal Protective Equipment (PPE) for Coronavirus Disease (COVID-19): Interim Guidance, 19 March 2020, World Health Organization, Geneva, Switzerland, 2020, https://www.who.int/publicationsdetail/rational-use-of-personal-protective-equipment-for-coro navirus-disease-(covid-19)-and-considerations-during-severeshortages.

[10] S. Bialek, E. Boundy, V. Bowen et al., "Severe outcomes among patients with coronavirus disease 2019 (COVID-19)_United States, February 12-March 16, 2020," Morbidity and Mortality Weekly Report, vol. 69, pp. 343-346, 2020.

[11] S. K. Gudi, K. Undela, R. Venkataraman et al., "Knowledge and beliefs towards universal safety precautions to flatten the curve during novel coronavirus disease (nCOVID-19) pandemic among general public in India: explorations from a national perspective," medRxiv, 2020.

[12] K.-f. W. E. Ho, K. F. Ho, S. Y. Wong, A. W. Cheung, and E. Yeoh, "Workplace safety and coronavirus disease (COVID19) pandemic: survey of employees," Bulletin of the World Health Organization, 2020.

[13] World Health Organization, Coronavirus Disease (COVID-19) Training, https://www.afro.who.int/publications/coronavirusdisease-covid-19-training-online-training.

[14] World Health Organization, Personal Protective Equipment in the Context of Filovirus Disease Outbreak Response Rapid Advice Guideline: Summary of the Recommendations, World Health Organization, Geneva, Switzerland, 2014, https://apps. who.int/iris/handle/10665/137410.

[15] A. Wu, X. Huang, C. Li, and L. Li, "Novel coronavirus (2019$\mathrm{nCov}$ ) pneumonia in medical institutions: problems in prevention and control," Chinese Journal of Infection Control, vol. 19, pp. 1-6, 2020.

[16] J. Bowden, "More than 700 employees at one Detroit hospital system test positive for coronavirus," 2020, https:// thehill.com/homenews/state-watch/491484-more-than-700employees-at-one-detroit-hospital-system-test-positive-for.

[17] WhatsApp, 2019. About WhatsApp, https://www.whatsapp. com/about/.

[18] NOIPOLLs Limited, Social Media Poll Report-November 2019, 2020, https://noi-polls.com/wp-content/uploads/2019/ 11/Social-Media-Poll-Report.pdf.

[19] M. O. Araoye, Research Methodology with Statistics for Health and Social Sciences, Nathadex Publishers, Ilorin, Nigeria, 2003.

[20] Google form Document Questionnaire, Assessment of Health Workers' Knowledge, Beliefs, Attitudes and Use of Personal Protective Equipment for Prevention of COVID 19 Infection in Low Resource Settings, https://docs.google.com/forms/d/e/ 1FAIpQLScUWQqSwOvv-7gNiEHxDzk0opv6GapgdQuKDB wiRTsj8a_1_Q/viewform?usp=sf_link.

[21] C. W. Kassahun and A. G. Mekonen, "Knowledge, attitude, practices and their associated factors towards diabetes mellitus among non diabetes community members of Bale zone administrative towns, South East Ethiopia. A cross-sectional study," PLoS One, vol. 12, no. 2, Article ID e0170040, 2017.

[22] A. A. Azlan, M. R. Hamzah, T. J. Sern, S. H. Ayub, and E. Mohamad, "Public knowledge, attitudes and practices 
towards COVID-19: a cross-sectional study in Malaysia," PLoS One, vol. 15, no. 5, Article ID e0233668, 2020.

[23] E. N. Aguwa, S. U. Arinze-Onyia, and A. Ndu, "Use of personal protective equipment among health workers in a tertiary health institution, South East Nigeria: pre-ebola period," International Journal of Health Sciences and Research, vol. 6, pp. 12-18, 2016.

[24] R. R. M. Gershon, K. A. Qureshi, M. Pogorzelska et al., "Nonhospital based registered nurses and the risk of bloodborne pathogen exposure," Industrial Health, vol. 45, no. 5, pp. 695-704, 2007.

[25] D. Moore, B. Gamage, E. Bryce, R. Copes, and A. Yassi, "Protecting health care workers from SARS and other respiratory pathogens: organizational and individual factors that affect adherence to infection control guidelines," American Journal of Infection Control, vol. 33, no. 2, pp. 88-96, 2005.

[26] S. E. Chia, D. Koh, C. Fones et al., "Appropriate use of personal protective equipment among healthcare workers in public sector hospitals and primary healthcare polyclinics during the SARS outbreak in Singapore," Occupational and Environmental Medicine, vol. 62, no. 7, pp. 473-477, 2005.

[27] L. T. Phan, D. Maita, D. C. Mortiz et al., "Personal protective equipment doffing practices of healthcare workers," Journal of Occupational and Environmental Hygiene, vol. 16, no. 8, pp. 575-581, 2019.

[28] J. H. Kwon, C.-A. D. Burnham, K. A. Reske et al., "Assessment of healthcare worker protocol deviations and self-contamination during personal protective equipment donning and doffing," Infection Control \& Hospital Epidemiology, vol. 38, no. 9, pp. 1077-1083, 2017.

[29] O. Atoyebi, D. Ojerinde, and T. Muntari, "COVID-19: infected health workers rise from 40 to 113 in one week," 2020, https://punchng.com/covid-19-infected-health-workers-risefrom-40-to-113-in-one-week/.

[30] C. D. McGaw, I. Tennant, H. E. Harding, S. O. Cawich, I. W. Crandon, and C. A. Walters, "Healthcare workers' attitudes to and compliance with infection control guidelines in the operating department at the university hospital of the West Indies, Jamaica," International Journal of Infection Control, vol. 8, no. 3, pp. 1-9, 2012.

[31] X. Hu, Z. Zhang, N. Li et al., "Self-reported use of personal protective equipment among Chinese critical care clinicians during 2009 H1N1 influenza pandemic," PLoS One, vol. 7, no. 9, pp. 1-7, 2012.

[32] F. S. Kilinc, "A review of isolation gowns in healthcare: fabric and gown properties," Journal of Engineered Fibers and Fabrics, vol. 10, no. 3, pp. 180-190, 2015. 